\title{
MERCADO SANITARIO PRIVADO Y TERRITORIO EN GALICIA. NEOLIBERALISMO Y NUEVAS PAUTAS DE COMPORTAMIENTO SOCIAL
}

\author{
Jesús M. González Pérez \\ Departament de Ciències de la Terra \\ Universitat de les Illes Balears
}

\section{RESUMEN}

La crisis del Estado del Bienestar, los procesos de reforma del sistema sanitario público y la introducción de la práctica privada en el Servicio Nacional de Salud (SNS) se inscriben en el contexto del neoliberalismo posmoderno. La devaluación del sistema público y la progresiva aceptación social hacia la regulación sanitaria a través de las leyes del mercado explican, por un lado, el reforzamiento de la práctica sanitaria privada y, por otro, la extensión de un modelo de gestión y planificación dominado por las compañías de seguros médicos privados. El aumento en el número de primas y de su facturación en los últimos años son expresión de la confianza que el sector privado significa para las clases sociales más acomodadas del país.

La distribución de las distintas tipologías hospitalarias (por finalidad asistencial y tamaño) en Galicia se superponen a la jerarquía (poblacional, económica y funcional) de la red urbana. El papel regulador del mercado impone una estrategia de distribución territorial marcada por la búsqueda de clientes de un determinado poder adquisitivo. No obstante, la potencialidad económica y la proyección del sector todavía se encuentran demasiado supeditadas a las políticas públicas, al establecimiento de conciertos con el Servicio Galego de Saúde.

Palabras clave: sanidad privada, neoliberalismo, seguro médico privado, hospital, red urbana.

\begin{abstract}
Private health market and territory in Galicia. New-liberalism and new lines in the social behavior. The Welfare State crisis, the processes of reform in the public health system and the introduction of the private market in the National Health Service can be inscribed in the framework of the post-modern new-liberalism. The devaluation of the public system and the progressive social acceptation of the sanitary regulation by means of the market rules explain, on the one hand, the reinforcement of the private sanitary practices and, on the other hand, the extension of a managerial model dominated by the health insurance private companies. In the last years, the increase in both the number of insurance policies and the corresponding income
\end{abstract}


are a direct expression of the trust that the private sector represents for the highest level social classes of the country.

The distribution of the different hospital typologies (by assistance purpose and dimensions) in Galicia is overlapped to a hierarchy (economic and functional) of the urban network. The regulatory role of the market imposes an strategy of the territorial distribution characterised by an aimed search of costumers with a given economic level. However, the economic potential and the projection of the sector still depend strongly on the public policies, i.e., on the establishments of agreements with the Galician Health Service.

Key words: private health system, new-liberalism, private health insurance, hospital, urban network.

Durante los años cincuenta y sesenta, la prosperidad económica y el desarrollo social fueron una evidencia en la mayoría de los países europeos occidentales. Conservadores y socialdemócratas coincidían básicamente en los postulados socioeconómicos y, por primera vez, la política económica del momento no concebía su propio desarrollo sin los postulados de igualdad social. En España, la distancia ideológica y política del régimen franquista imposibilita cualquier tipo de consenso en este tipo de políticas.

Las dificultades para la asunción de discursos sociales de corte socialdemócrata durante el período de la transición y el primer gobierno democrático en España, encuentra respuesta antes de que finalice la primera década sin dictadura militar. A mediados de los años ochenta, que coincide con el final del primer mandato de Partido Socialista Obrero Español (PSOE), se aprueba toda una serie de leyes estatales (de sanidad, educación, patrimonio, algunas de ordenación del territorio...) de enorme trascendencia para el panorama social y económico del país, y que se enmarcan en los principios del Estado del Bienestar que tan excelentes resultados estaban obteniendo en los países europeos occidentales desde finales de la Segunda Guerra Mundial. Sin duda, la evolución normativa facilitaba un acercamiento progresivo a los lejanos niveles de calidad de vida de las anheladas y envidiadas naciones europeas. Aún con el evidente retraso con respecto al resto de países de nuestro entorno, los avances en política social son patentes durante la siguiente década en España. No obstante, esta aceleración en la incorporación de modernos principios de economía social no tardaron en ponerse en entredicho. La causa se encuentra en la entrada en un nuevo período caracterizado por la crisis del Estado del Bienestar. El tradicional alejamiento ideológico y social de España con respecto al resto de Europa se acorta al final de esta etapa, con la fácil incorporación por parte de aquélla al pensamiento generalizado de crisis del Welfare State, cuando prácticamente no había tenido tiempo de disfrutar de sus ventajas.

La situación ideológica y económica de los años ochenta se puede caracterizar por un relanzamiento de la ideología liberal-conservadora y la existencia de un desigual y moderado crecimiento económico en la segunda mitad del decenio hasta que, de nuevo, la crisis económica nos vuelve a afectar con fuerza. Esto se traducirá en un considerable aumento del número de desempleados, tasas de crecimiento negativas, deslocalización de las inversiones... que llevan a los gobiernos a actuar sobre la política social para lograr un nuevo despegue económico. Esta situación de crisis está siendo propagada hasta tal punto que el propio sistema de seguridad social, reflejo del desarrollo del Welfare State, es acusado de provocar la crisis económica, cuando no es más que un derecho adquirido en forma de defensa del sistema capitalista. Y una de las fórmulas más comunes y directas puesta en práctica en la actualidad para reducir el Estado del Bienestar es aumentar la provisión pri- 
vada vía mercado en contra de unos servicios públicos que se quieren demostrar como ineficientes y costosos.

Sin embargo, esta tendencia creciente hacia el proceso privatizador, incluso de unos servicios públicos considerados hasta hace pocos años como elementales, puede ser más un efecto de la ideología dominante que de las circunstancias socioeconómicas que estamos viviendo. Pensemos como la etapa de crisis posbélica es superada en la mayoría de los países de Europa occidental con políticas socialdemócratas de potenciación del sector público. Al contrario, durante los últimos años de crecimiento económico generalizado, las posiciones político-ideológicas (herederas de la crisis del Estado del Bienestar) abogan por el «adelgazamiento del Estado» como una de las medidas para contener el gasto público, reducir la burocracia administrativa y para facilitar la supuesta devolución a los ciudadanos de su libertad y capacidad de iniciativa (Sánchez, 1998b; 13). Estas políticas neoliberales explican la creciente privatización del sector público productivo y de servicios, la drástica contención del gasto público (reforzada por los criterios de Maastricht para la convergencia europea y por los acuerdos de control de gasto para la moneda única), la desregulación de la economía y de la vida social, etc. (Sánchez, 1998b; 15-17). Mientras tanto, muchas de las acciones de reequilibrio y cohesión social, tan protegidas por el Estado en los últimos cincuenta años en Europa, son dirigidas cada vez más por instituciones benéficas, voluntariado o por organizaciones informales y no gubernamentales. Ante estas transformaciones, algunos autores prefieren hablar de «una crisis ideológica de confianza en el Estado del Bienestar de postguerra» (Mishra, 1989; 57), por lo que son razones ideológicas las que lleven a los propios gobiernos a propagar la idea de crisis de Estado del Bienestar, como simple objetivo de reducir gastos sociales (Johnson, 1990; 76). En definitiva y de acuerdo con el profesor Fernando Esteve, «la crisis económica real que han padecido los Estados del Bienestar de las economías occidentales se ha solapado con una crisis teórica de los fundamentos del Estado del Bienestar, con el consiguiente efecto de achacar a las políticas de bienestar la responsabilidad de la crisis... ...por ello resulta necesario reflexionar teóricamente sobre esas pretendidas crisis teóricas del Estado del Bienestar» (Esteve, 1989; 103).

Este cambio ideológico constituye la principal causa del fortalecimiento de los servicios sanitarios privados y de una modificación en la percepción de los ciudadanos que, cada vez más, desconfían del sistema público y optan por una más «eficiente» atención proporcionada por la sanidad privada, atendiendo a la lógica capitalista y a la nueva y creciente visión conservadora de la población joven de recursos medios y elevados, reafirmado en las últimas elecciones generales en España. Aún así, lo que resulta más preocupante es que uno de los principales culpables de esta pérdida de credibilidad hacia el sistema social proporcionado por el Estado sean los propios poderes públicos, tal y como Johnson ya adelantó con respecto a los inicios de la divulgación de crisis del Welfare State (Johnson, 1990; 76). Ellos mismos aluden constantemente a la dificultad de sostener el actual sistema de prestaciones, nadie es ajeno a la constante desinversión que conocen muchos de nuestros servicios públicos (como le ocurre a la sanidad) y no resulta fácil comprender cómo el Estado facilita a sus propios empleados la posibilidad de elección en la utilización de un servicio que es ajeno a su propiedad y gestión, como sucede con las compañías de seguros sanitarios privados para los funcionarios. En una palabra, la administración pública no sólo parece no confiar sino que además busca el debilitamiento, en base al descenso en el número de demandantes, de los servicios que ella misma administra.

La crítica conservadora al Estado del Bienestar defiende el restablecimiento de las leyes de mercado y la política monetaria para así reducir la inflación y rebajar el gasto público, al 
tiempo que se potencia la inversión y la iniciativa privada. Esta tendencia y el liberalismo posmoderno contribuyen a que a los elementos materiales tradicionales que expresan ascenso en la clase social (vivienda unifamiliar periurbana, acceso a un automóvil de gama elevada, disfrute de unas vacaciones a poder ser en otro continente...) se añada ahora la utilización de una serie de servicios privados, como los relativos a la sanidad y educación, que marcan claramente un nivel social y económico destacado en la comunidad. Todas estas transformaciones estructurales y comportamentales en la sociedad se traducen en una particular prestación de servicios y en unos modelos de distribución territorial de recursos dirigidos por la búsqueda de un determinado mercado.

Estos elementos de análisis, algunos realmente complejos y que obligarían a una interpretación sociológica más profunda, establecen las bases para el análisis de un servicio, como es la sanidad privada, a la que se le ha prestado escasa atención desde una perspectiva geográfica. Los cambios que está conociendo el sector, su relativo fortalecimiento, lo que puede representar para la sanidad en su conjunto y para la pública en particular, sus modelos de distribución territorial o la mejora de imagen de sus servicios apoyado también en costosas inversiones publicitarias nos anima a prestarle una especial atención. Por último, a pesar de que el territorio de estudio (Galicia) pueda parecer no demasiado apetecible para la lógica privada, debido a su todavía importante porcentaje de población rural y por poseer un nivel de desarrollo económico por debajo de la media estatal, resulta un interesante escenario para estudiar la comunión o la competencia, según los casos, entre el capital privado y el modelo público. No olvidemos que a pesar de todas las transformaciones socioeconómicas, el sector público constituye el principal cliente de la práctica sanitaria privada a través del afianzamiento de los conciertos con la sanidad pública.

\section{La oferta médica privada: del profesional liberal al dominio de las compañías de seguros}

Alrededor del 99,2\% de la población gallega cuenta con una cobertura sanitaria de carácter público a través de una de las tres modalidades según su financiación: la Seguridad Social, la Beneficiencia y las Mutualidades del Estado (a su vez acogidas a la Seguridad Social o a seguros privados). La financiación privada (substitutoria o complementaria) está formada por los seguros médicos privados o de asistencia sanitaria, los concertados de empresa, las igualas médicas o el tradicional recurso al médico privado propiamente dicho (Fernández-Mayoralas, G. y Rodríguez, V., 1997; 378).

La medicina privada es el máximo exponente de la concepción liberal de la profesión. Bajo este concepto, el médico y las clínicas privadas son sus prestadores habituales. Hasta hace pocos años, la práctica privada más común era la prestación de servicios en la propia consulta, sin intermediación de ninguna compañía de seguros y mediante el pago por acto médico. Dada la escasez de personal sanitario, los servicios médicos privados constituían una actividad casi exclusivamente del mundo urbano. Los espacios rurales concentraban escasa presencia del sector privado debido, por un lado, a los más bajos recursos de su población y, por otro, a que las ciudades se mostraban como espacios más atractivos y con superior número de clientes para la instalación de un reconocido y ampliamente valorado profesional liberal como era el médico. Según las necesidades, el médico desviaba al paciente a una clínica o sanatorio también privado en el caso de necesitar determinadas pruebas diagnósticas o cirugía. 
Las intensas transformaciones que se han producido en la sociedad y economía gallega en las últimas dos décadas influyen en un importante cambio en la estructuración del sector. Los usuarios de la medicina privada cada vez más acceden a sus consultas a través de las prestaciones ofrecidas por un seguro de asistencia sanitaria privado que incluyen en sus carteras de servicios atención médica general, especializada, quirúrgica y de rehabilitación. Pocos profesionales subsisten con el pago privado por acto médico, salvo algunos de muy reconocido prestigio, formando parte, la práctica totalidad de los mismos, de las carteras de las más diversas compañías de seguros.

Por tanto, el denominado seguro de asistencia sanitaria es aquel que proporciona al asegurado y a sus beneficiarios asistencia médica, hospitalaria y quirúrgica, en caso de enfermedad o accidente, a través de un cuadro médico de facultativos y centros asistenciales, clínicas y hospitales, con los que el asegurador ha suscrito un contrato de servicios. Sus actuaciones se basan en la libertad de elección, a pesar de que los cuadros médicos son fijos y rígidos, sin que exista posibilidad de optar por un profesional o centro externo a ese cuadro. Además, están excluidas importantes coberturas y en muchas ocasiones existen exclusiones entre los propios asegurados. Son el caso de la prestación farmacéutica, prótesis, diálisis, enfermedades del corazón, epilepsia, síndrome de Down, diabetes, SIDA o, tal y como hace más de una compañía, tener más de 65 años de edad.

La concentración económica, organizativa y de decisión de la medicina privada en estas compañías caracteriza la evolución del sector en los últimos diez años. Las aseguradoras no sólo dominan la demanda (el paciente o cliente) sino que controlan la oferta. $\mathrm{Su}$ alto poder de decisión influye incluso en la adopción de fórmulas para la gestión de los recursos humanos de las clínicas y hospitales, que le suponen un interesante ahorro económico. Es decir, la mayoría del personal sanitario que ejerce sus funciones en estos centros no forma parte de la plantilla de la empresa o de la compañía de seguros. Los hospitales no tienen en plantilla a todos los facultativos que figuran en sus carteras, dado que estos actúan como profesionales libres («médicos colaboradores»), trabajando habitualmente a través de compañías de seguros médicos privados. Estos facultativos realizan la mayoría de las consultas externas del hospital y se encargan de la hospitalización propiamente dicha. Se trata de un arrendamiento de servicios que proporciona un interesante ahorro en personal. Pero por el contrario, este sistema contribuye a que el médico esté más preocupado por el beneficio personal que por un funcionamiento integrado de la clínica. El modelo puede provocar una infravalorización del empleo pero, en ocasiones, puede dar lugar a duplicación de puestos de trabajo. Y sino pensemos en el médico que comparte su dedicación entre su consulta particular y el sanatorio privado. Pues bien, se calcula que el 90\% de todos los facultativos de los hospitales privados gallegos actúan como médicos colaboradores y, por tanto, no forman parte de las respectivas plantillas de los centros (González, 1999; 88).

Estas entidades de seguro libre facturaron por primas en España un total de 335.361 millones de pesetas en 1998, cuando sólo sumaban unos 200.000 millones hace menos de una década. Unos ingresos a nivel estatal que superan los 313.619 millones de pesetas de gasto real del Sistema Nacional de Salud en Galicia en 1999. Después del ramo de seguros de automóviles (882.905 millones de pesetas) es la modalidad de seguros no de vida con mayores ingresos. Unas cifras que ponen de manifiesto tanto la creciente importancia que está adquiriendo el sector privado en la sanidad, como la rentabilidad que supone este sector para las compañías de seguros, de ahí que muchas estén incorporando en sus servicios los relativos a la atención a la salud. 
El conjunto del sector de los seguros creció en España más del 25\% durante 1999. Excepto Navarra y Castellón, todas las provincias han aumentado su volumen de negocio en 1999. En Galicia destaca Ourense, con un crecimiento relativo superior a la media estatal. Pues bien, del volumen de negocio total (unos 5,4 billones de pesetas) un 13,86\% se corresponde con los de salud (enfermedad y asistencia sanitaria). Más concretamente, el de asistencia sanitaria suma 309.904,93 millones de pesetas en España (1999), un 9,73\% más que el año anterior.

Por su parte, el seguro de salud en Galicia está ampliamente dominado por el de asistencia sanitaria, al concentrar más del $90 \%$ de los 12.750 millones del volumen de negocio total del de salud. El presupuesto sanitario privado en pólizas de seguros en Galicia representa una media de 4.345 pesetas por habitante en 1999 , en tanto que el presupuesto público del Servicio Galego de Saúde (SERGAS) per cápita asciende a 115.109 pesetas en este mismo año.

Las cuatro provincias mantienen una evolución altamente positiva con respecto a 1998, si bien el fuerte crecimiento en Ourense se puede explicar por su reducida inversión de partida, sobre todo si la comparamos con una provincia de características económicas y demográficas similares como es Lugo. No obstante, las provincias occidentales son las que concentran el negocio en Galicia, en consonancia con su superior nivel económico y más efectivos demográficos. La mayor presencia de asegurados y de ingresos económicos en este territorio tiene, como podremos observar más adelante, una relación directa con la concentración de hospitales en A Coruña y Pontevedra.

Tabla 1

COBERTURA SANITARIA EN ESPAÑA, 1993. PORCENTAJE DE POBLACIÓN

\begin{tabular}{|l|r|l|r|}
\hline \multicolumn{2}{|c|}{ Cobertura pública } & \multicolumn{2}{c|}{ Cobertura privada } \\
\hline Seguridad Social & $91,7 \%$ & Seguros médicos & $4,4 \%$ \\
Beneficiencia & $0,4-1,0 \%$ & Concertados de empresa & $2,0 \%$ \\
Mutualidades del Estado & $7,5 \%$ & Igualas médicas & $0,8 \%$ \\
& & Médico privado (acto médico) & $0,4 \%$ \\
\hline TOTAL & $99,6 \%$ & TOTAL & $7,6 \%$ \\
\hline
\end{tabular}

Fuente: Dirección General de Aseguramiento y Planificación Sanitaria. Ministerio de Sanidad y Consumo.

Tabla 2

DISTRIBUCIÓN DEL VOLUMEN DE NEGOCIO EN GALICIA

\begin{tabular}{|l|r|r|r|c|}
\hline \multirow{2}{*}{} & \multicolumn{2}{|c|}{ Salud } & \multicolumn{2}{c|}{ Asistencia sanitaria } \\
\cline { 2 - 5 } & $\begin{array}{c}\text { Volumen } \\
\text { negocio 1999 }\end{array}$ & $\begin{array}{c}\text { Incremento } \\
\mathbf{1 9 9 8 / 1 9 9 9}\end{array}$ & $\begin{array}{c}\text { Volumen } \\
\text { negocio 1999 }\end{array}$ & $\begin{array}{c}\text { \% sobre el } \\
\text { total salud }\end{array}$ \\
\hline A Coruña & 6.218 .983 & $3,00 \%$ & 5.835 .757 & 93,83 \\
Lugo & 1.355 .900 & $4,88 \%$ & 1.261 .203 & 93,01 \\
Ourense & 562.997 & $20,75 \%$ & 449.981 & 79,92 \\
Pontevedra & 4.608 .318 & $14,22 \%$ & 4.292 .527 & 93,14 \\
\hline GALICIA & 12.746 .198 & $8,04 \%$ & 11.839 .468 & 92,88 \\
\hline
\end{tabular}

Fuente: Instituto Atlántico del Seguro (INADE) e ICEA. 
Esta diferencia económica a favor de las dos provincias occidentales se corresponde con la distribución total del número de primas, aunque no con su representación relativa dada la importancia que adquiere este tipo de seguro en Pontevedra. Justamente la provincia que contabiliza más hospitales y camas de la Comunidad Autónoma. Si calculamos que cada prima equivale a una persona asegurada, siete de cada 100 personas poseen algún tipo de seguro médico privado en Pontevedra por menos de dos en Ourense.

Reconocidos expertos (Fernández-Mayoralas y Rodríguez, 1997; 389-392) han cartografiado un modelo geográfico de distribución de la cobertura total y exclusiva de los seguros médicos privados para todo el Estado. En él, los principales ejes de desarrollo y los nuevos espacios emergentes obtienen los indicadores más positivos de cobertura exclusiva: Madrid, Catalunya, Illes Balears, Euskadi, Navarra, Aragón y Murcia. A pesar de que Galicia obtiene índices más reducidos, los factores que influyen en su distribución a nivel intrarregional coinciden con los detectados por estos autores a escala estatal. La mayor cobertura de seguro médico privado se detecta en espacios de economía urbana y desarrollada debido a cuatro elementos fundamentales: rentas más elevadas que determinan una mayor capacidad de compra; la situación profesional del cabeza de familia; factores perceptivos negativos de la sanidad pública con respecto a la privada, que influyen en la progresiva implantación de centros privados en busca de potenciales clientes de importante poder adquisitivo; factores sociodemográficos que influyen sobre todos los elementos anteriores, como son la estructura por edad y sexo, la composición familiar, etc.. Pero a estos factores, se pueden añadir otros dos de gran importancia. Por un lado, el fortalecimiento del pensamiento neoliberal y la desconfianza en el sistema público, auspiciado desde instancias gubernamentales pero fácilmente asumido por parte de una buena parte de la población de ingresos medios y elevados. Y por otro, la posibilidad de elección de los funcionarios públicos entre el sistema de Seguridad Social y el de seguros médicos privados. Esta decisión ha motivado una fuerte inversión por parte de las compañías aseguradoras en el sector salud en busca de un mercado amplio y creciente que, además, coincide con una buena parte de esa población joven y adulta de aceptable nivel económico. Tengamos en cuenta que de las 136.637 personas que trabajan para la administración pública en Galicia (2000), una importante representación se concentra en A Coruña y sobre todo en Santiago de Compostela (Xunta de Galicia), lo que contribuye a explicar el elevado volumen de negocio de los seguros de asistencia sanitaria en la provincia coruñesa.

Diversos trabajos elaborados a nivel estatal afirman que entre un $70 \%$ y $80 \%$ de la población que contrató una póliza directa o voluntaria está a su vez protegida por la Seguridad Social (Fernández-Mayoralas y Rodríguez, 1997; 383) (Hernández, 1989; 14). En Galicia, el grupo de personas con doble cobertura se sitúa en torno al 6\% (González, 1999; 128). Lo habitual en esta Comunidad es el acceso a la medicina prestada por el sector privado para consultas externas y pruebas diagnósticas y terapéuticas y, secundariamente, para

Tabla 3

DISTRIBUCIÓN DEL NÚMERO DE PRIMAS DE SEGUROS DE ASISTENCIA SANITARIA, 1999

\begin{tabular}{|l|c|c|c|c|c|}
\hline & A Coruña & Lugo & Ourense & Pontevedra & GALICIA \\
\hline Número de primas & 66.435 & 19.163 & 6.327 & 63.922 & 155.847 \\
\% sobre ${ }^{\circ}$ habitantes & 6,00 & 5,21 & 1,83 & 7,05 & 5,72 \\
\hline
\end{tabular}

Fuente: Investigación Cooperativa entre Entidades Aseguradoras (ICEA). 
cirugía rápida y sencilla. Desde siempre, y por nuestra propia percepción, pensamos que a medida que se incrementa el grado de afección de una enfermedad y las necesidades quirúrgicas o de pruebas especializadas son más habituales, el paciente tiende a desplazarse a los servicios ofertados desde el sistema público, probablemente debido a la falta de confianza en nuestro sector hospitalario privado. No obstante, un reciente estudio elaborado por la Consellería de Sanidade e Servicios Sociais de la Xunta de Galicia (1997) demuestra lo contrario: se incrementa la valoración positiva del sector privado a medida que aumenta el grado de afección de la enfermedad. Ante problemas de salud leves, el 8,1\% de los pacientes se dirigen al sistema privado (89,3\% al público). Cuando el problema es grave, el 25,2\% de la población opta por el privado y el 71,3\% por el ofertado desde el público.

$\mathrm{Al}$ igual que en el resto de España, en Galicia es característica la concentración del volumen de negocio y las primas de seguros de asistencia sanitaria en unas pocas entidades. Exceptuando la cuota que representa Asisa (la principal empresa del mercado asegurador médico en España que no ha facilitado los datos a ICEA), sólo once entidades tienen representación en el mercado gallego. De éstas, únicamente cuatro suman un volumen de negocio superior a los 100 millones de pesetas en 1999 y una de ellas (Adeslas) concentra el $80,29 \%$ de los ingresos del sector.

Tabla 4

VOLUMEN DE NEGOCIO (EN MILES DE PTAS.) DE LAS PRINCIPALES ENTIDADES ASEGURADORAS DE ASISTENCIA SANITARIA EN GALICIA, 1999

\begin{tabular}{|l|l|r|l|l|r|}
\hline \multirow{2}{*}{ A Coruña } & Adeslas & 4.772 .000 & Ourense & Adeslas & 273.000 \\
& Sanitas & 801.076 & & Sanitas & 92.637 \\
& Aegon & 152.782 & & DKV Previasa & 44.166 \\
\hline \multirow{2}{*}{ Lugo } & Adeslas & 1.118 .000 & Pontevedra & Adeslas & 3.341 .000 \\
& Sanitas & 91.343 & & Aegon & 540.913 \\
& Caja Madrid Seguros & 33.533 & & Sanitas & 323.569 \\
\hline
\end{tabular}

Fuente: ICEA.

En definitiva, estamos asistiendo a un verdadero fortalecimiento de la sanidad privada sustentada en las estrategias de promoción de los seguros de asistencia sanitaria. Por unas u otras razones, el Estado del Bienestar agudiza su crisis, si bien la mayoría de los partidos políticos siguen incluyendo en sus discursos la necesidad del mantenimiento del Welfare State por evidentes cuestiones electorales, aunque ellos mismos son conscientes de su debilitamiento. Una crisis que se convierte en irreversible desde el momento en el que las compañías de seguros se autoproclaman como los nuevos sustentadores del Estado del Bienestar (suplemento especial sobre los seguros: Faro de Vigo, 19-3-1999).

\section{La distribución territorial de los dispositivos de prestación sanitaria privada: el sector hospitalario}

Todos los subsectores que componen el sector sanitario privado en Galicia contabilizan más de 2.000 centros asistenciales de todos los tamaños, proporciona empleo directo a más de 7.500 personas y factura anualmente unos 60.400 millones de pesetas (González, 1998 y 
1999). Unas cifras de empleo que se acercan a la proporcionada por la factoría Citroën radicada en Vigo, primera empresa en facturación y número de empleados en Galicia, donde trabajan 8.069 personas aunque con una facturación muy superior, en torno a los 458.926 millones de pesetas en 1998. De esto se intuye el excepcional dinamismo de este sector privado y como consecuencia una particular impronta territorial intensamente relacionada con la búsqueda de un determinado mercado. Se trata de un sector que genera valor añadido, es uno de los ámbitos que más puestos de trabajo produce y que mueve presupuestos más importantes, crea externalidades y posee una gran capacidad de arrastre sobre otros sectores económicos. El análisis de la sanidad privada lo vamos a centrar en el hospitalario, tanto por su importante impacto territorial como por su mayor relación con la red urbana y la organización del espacio regional.

La hospitalización privada en España desempeña un papel muy desigual y posee un prestigio muy diferente según la Comunidad Autónoma a la que hagamos mención. El más bajo nivel de desarrollo socioeconómico de Galicia, que influiría en una menor presencia del sector, es parcialmente compensado con los nuevos comportamientos sociales hacia una atención privada más personalizada y por las políticas restrictivas del gasto público sanitario gallego, que irremediablemente influyen en una pérdida de calidad asistencial. Las camas instaladas privadas en Galicia alcanzan las 2.898 (el 25,87\% de las totales) en el 2000. Con respecto a décadas pasadas se constata una reducción de los hospitales privadobenéficos, esencialmente propiedad de la Iglesia o de otras congregaciones religiosas, y un mantenimiento o ligero descenso de los no benéficos, cada vez más gestionados por compañías aseguradoras incluso de capital extranjero (caso de la empresa de los EE.UU. United Surgical Partners, dedicada a la gestión hospitalaria, con la adquisición del Instituto Policlínico Santa Teresa de A Coruña en 1998).

La articulación del sector hospitalario privado denota una fuerte concentración en las dos provincias occidentales, que directamente se puede relacionar con mayores dotaciones humanas y tecnológicas. El superior dinamismo demográfico y económico del territorio occidental, la obtención de tasas de envejecimiento más bajos, sus mayores índices de población urbana, la localización del eje urbano más importante del país (Eje Atlántico) o una estructura económica dominada por los sectores terciario y secundario explican una demanda de servicios especializados característico de espacios urbanos con altos niveles de vitalidad.

La distribución de los hospitales por el territorio ha sido, hasta fecha muy reciente, el resultado de una especie de generación espontánea, a merced de las iniciativas caritativas

Tabla 5

CENTROS HOSPITALARIOS Y CAMAS INSTALADAS DE PROPIEDAD PRIVADA, 2000

\begin{tabular}{|l|c|c|c|}
\hline & Número de centros & Camas instaladas & Camas/1.000 habitantes \\
\hline A Coruña & 15 & 1.124 & 1,01 \\
Lugo & 2 & 156 & 0,42 \\
Ourense & 4 & 158 & 0,45 \\
Pontevedra & 18 & 1.460 & 1,61 \\
\hline GALICIA & 39 & 2.898 & 1,06 \\
\hline
\end{tabular}

Fuente: Consellería de Sanidade e Servicios Sociais. 
del pasado, de la capacidad de decisión de una comunidad urbana o de la voluntad de poder de una autoridad electa local. Tan solo desde hace unos veinte años, un sistema público de salud jerarquizado y coherente tiende a ordenar el territorio. Sin embargo, el privado mantiene una serie de comportamientos muy distantes de lo que es la propia planificación como servicio público, y su expansión se produce únicamente por la búsqueda de mercado, de pacientes o, como algunos los prefieren denominar, clientes.

Las representaciones gráficas ponen de manifiesto, por un lado, la potencialidad de la hospitalización privada en A Coruña y Pontevedra, y por otro la polarización sanitaria en las principales ciudades de la Comunidad Autónoma. La concentración hospitalaria en el oeste gallego se corrobora con la distribución de los dispositivos por Áreas de Saúde. La utilización de este ámbito territorial, de aplicación para la sanidad pública, reafirma el nulo interés del privado por el espacio o áreas de salud rurales del este gallego (Cervo, Monforte y $\mathrm{O}$ Barco) y confirma la importancia de la aplicación de los mapas de salud en la delimitación de zonas funcionales donde, se ubicarán los servicios sanitarios que se pondrán al alcance de la población ${ }^{1}$. Para este caso, cada área de salud debe contar con su respectivo hospital general público de referencia, procurando de este modo una sanidad accesible, universal e igualitaria para toda la población independientemente su lugar de residencia.

Tal y como sucede con el hospital público, los centros privados se superponen sobre el sistema de ciudades. El modelo de distribución de dispositivos en Galicia guarda una estrecha relación con la organización del espacio y con la red urbana del país. Las ciudades más importantes y articuladoras de la red urbana son las que concentran los recursos hospitalarios, dejando casi sin representación (al contrario que el público) a las vilas o pequeñas ciudades que no resultan interesantes para el capital privado. En los últimos cinco años asistimos a la inauguración de siete hospitales comarcales públicos, al tiempo que cerraron dos pequeños sanatorios privados en cabeceras comarcales interiores: O Carballiño y Monforte. Hoy en día sólo se mantienen abiertos clínicas privadas con internado en Lalín y Vilagarcía de Arousa, aunque con un futuro incierto. El resto de hospitales no urbanos responden a localizaciones periféricas a ciudades rectoras como son los casos de las ubicaciones periurbanas en Poio y Bergondo, así como un caso particular y de interesante análisis en el municipio rural de Serra de Outes.

La potencialidad urbana y la extensión de las áreas de influencia definen la dotación hospitalaria de cada una de las ciudades. Aunque pueda parecer un tanto arriesgado, se puede llegar a establecer un modelo en la localización de los equipamientos en base a su tamaño y finalidad asistencial, y dependiendo de la posición que ocupe la ciudad en la organización del espacio regional.

Las dos ciudades rectoras de la red urbana gallega concentran no sólo el mayor número de hospitales sino que también poseen la más extensa diversidad de sanatorios especializados. La red asistencial es lo suficientemente completa para ciudades de este tamaño, aunque un tanto superior en Vigo dado que el sector privado cuenta con un área de influencia más amplia. Por su parte, los centros de la capital coruñesa tienen la competencia de la capital autonómica, donde tradicionalmente ha ocupado un lugar destacado la función sanitaria. En

1 Las Áreas de Saúde son las estructuras fundamentales del sistema sanitario responsabilizadas de las gestión sanitaria de los centros y establecimientos comprendidos dentro de los límites territoriales de todas las prestaciones y programas sanitarios que desarrollen los mismos (Decreto 55/1989, de 5 de abril, por el que se aprueba el Mapa Sanitario de Galicia y revisiones de 1992 y 1998). Como nivel organizativo superior está directamente relacionado con la potencia organizadora de la red urbana regional. 


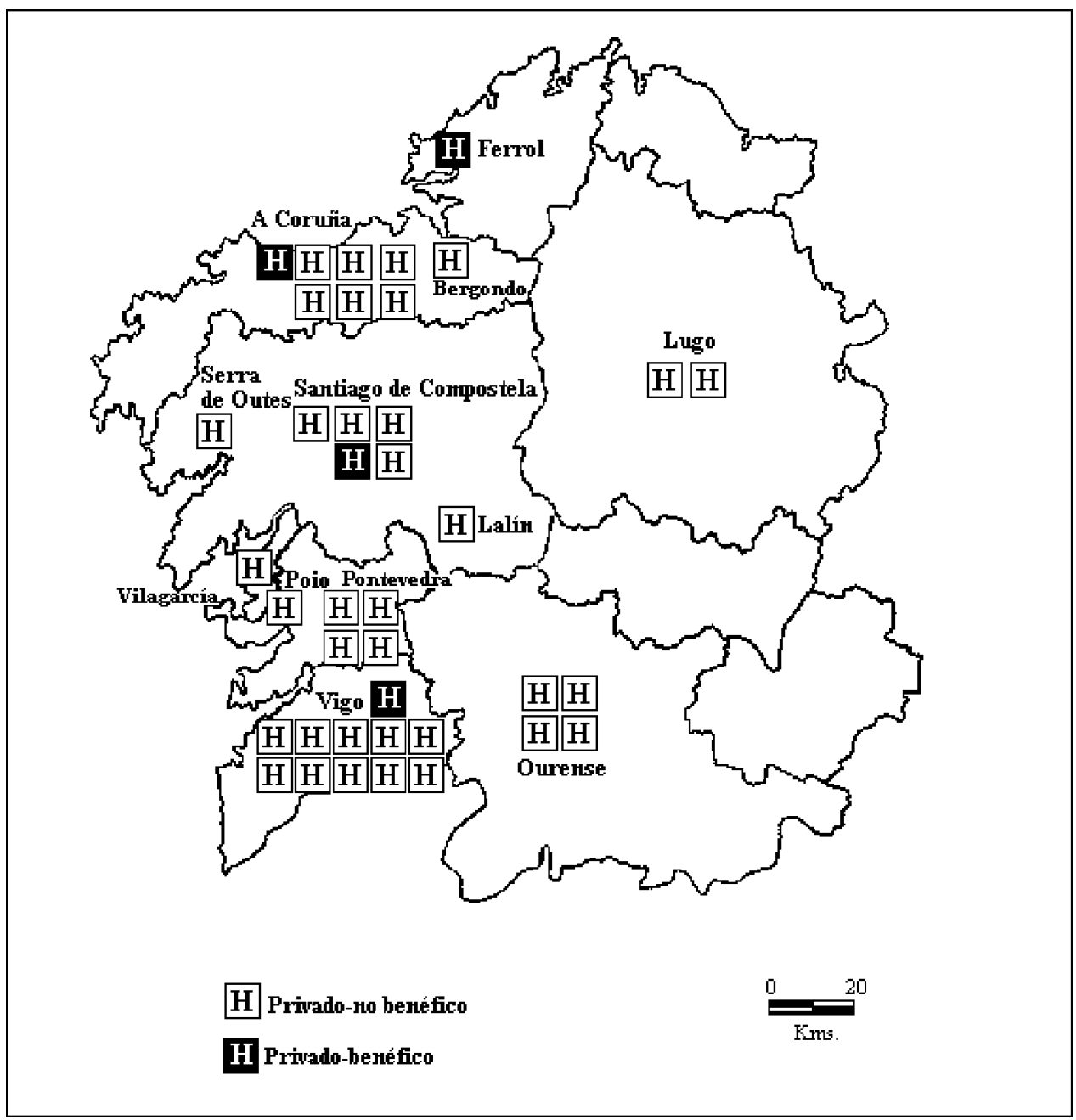

Fuente: Consellería de Sanidade e Servicios Sociais. Elaboración propia.

MAPA 1. Localización de la hospitalización privada por Áreas de Saúde.

un nivel superior, Vigo y A Coruña poseen tres hospitales generales de gran tamaño que actúan de referencia incluso para toda la provincia. Se trata del Centro Médico-Quirúrgico San Rafael (141 camas y 155 trabajadores en plantilla) en A Coruña y la Clínica Fátima (325 trabajadores y 200 camas) y el Policlínico Vigo S.A. (462 camas instaladas y más de 1.000 empleados) en Vigo. Este último es el más importante por camas instaladas y empleados de Galicia y, hasta hace pocos años, constituía el primer hospital de España por número de camas. No obstante, su actual potencialidad se asienta en un concierto especial con el SERGAS por el cual es hospital de referencia, por tanto con una funcionalidad pública, para 142.491 habitantes del Área de Saúde de Vigo. 
En un siguiente nivel, estas dos ciudades cuentan con una oferta más o menos extensa de hospitales generales y quirúrgicos de tamaño medio y pequeño que huyen de la especialización tecnológica y donde prima una atención más personalizada y ambiente familiar. Para esto es habitual que opten por localizaciones en lugares centrales de la ciudad pero poco masificados, con escasa densidad edificativa, pocos problemas de tráfico e incluso ubicándose en antiguos chalets reformados. Esto explica las localizaciones en la Ciudad Jardín de A Coruña y O Castro (barrio con morfología similar a una ciudad jardín que cuenta con una de las principales zonas verdes de la ciudad) en Vigo.

La especialización en el sector hospitalario se repite en ciudades de este rango: traumatológicos, maternidades y psiquiátricos. La especialización funcional es consecuencia de una determinada estrategia de desarrollo o, en ocasiones, de simple supervivencia. Habitualmente son de reducidas dimensiones, en espacios no congestionados y, para los psiquiátricos, localizados en barrios exteriores a la ciudad central. Por su parte, los materno-infantiles son los que mejor se asocian con la existencia de áreas de influencia con importante componente de población joven de recursos medios o elevados, donde su acceso marca un determinado status social. Por último, los centros benéficos son también de características similares y en ningún caso relacionados con la Iglesia: pertenecen a la Cruz Roja de Vigo (70 camas y 71 empleados) y a la Sociedad Española de Lucha contra el Cáncer de A Coruña (100 camas y 162 empleados).

Por lo tanto, Vigo y A Coruña presentan una estructura típica de ciudades de su rango urbano, con la presencia de uno o dos centros de grandes dimensiones, un segundo escalón con varios hospitales medios que cubren la demanda de determinados barrios de la ciudad y de su área de influencia próxima. Y a estos generales, se le añade un grupo de pequeños hospitales especializados en las finalidades asistenciales no generales que más se repiten en la asistencia privada en Galicia, como son la traumatológica, la psiquiátrica y la materno-infantil.

En un segundo nivel, el modelo dotacional en Santiago de Compostela, Ourense y Pontevedra difiere sobre todo por las menores dimensiones de los equipamientos y por una reducción en la especialización complementaria. Si bien los psiquiátricos y los quirúrgicos son comunes en dos de estas ciudades, la maternidad se reduce a Ourense. El traumatológico desaparece en este nivel, siendo exclusivo de las ciudades más pobladas, dinámicas y con importantes áreas de influencia.

Sobre todos ellos destaca la capital autonómica. Santiago de Compostela posee una oferta muy superior a la que le debería corresponder a una urbe de sus características, al menos desde un punto de vista poblacional. En este sentido, el dinamismo demográfico y socioeconómico de la capital de Galicia viene a completar una de las principales funciones de la ciudad en esta segunda mitad de siglo: la sanitaria. Las funciones religiosa, universitaria, turística, agropecuaria (feria de ganado), administrativa (Xunta de Galicia) y sanitaria son las principales que han caracterizado a esta ciudad durante las últimas décadas. Desde hace años y sobre todo con anterioridad a la creación del actual sistema de salud español, Santiago era punto de referencia para el sector sanitario gallego, no sólo público sino también privado. Una oferta completa y de calidad, reafirmada por la existencia de la única Facultad de Medicina de Galicia, conllevó a que su área de influencia sanitaria sobrepasase fácilmente los límites provinciales. En la actualidad, e independientemente de los centros públicos, Santiago mantiene parcialmente esta tradición al constatarse, en ocasiones por herencia, una importante red hospitalaria privada, similar a la que pudiera poseer una urbe de 200.000 habitantes, cuando escasamente alcanza los 100.000. Además, la presencia de un alto número de trabajadores públicos reafirma si cabe más esta función privada. Sin 
embargo, en esta oferta variada dominan los sanatorios medianos y sobre todo pequeños. La causa viene dada esencialmente por el papel jugado por el hospital público. Es decir, el Hospital Clínico Universitario, de nivel I y el único universitario de toda Galicia, tiene una difícil competencia por parte del sector privado. Su tamaño, avanzada tecnología y óptimos índices de calidad obligan a los privados a intentar completar la oferta más que entrar en competencia con este centro de referencia regional. Y más en una ciudad de menos de 100.000 habitantes y con un área de influencia con importante componente espacial rural. Esta situación dio lugar a que se inaugurasen toda una serie de centros privados pero en ningún caso superando las 100 camas. La función religiosa y el patrimonio eclesiástico en la ciudad compostelana explica que esta ciudad posea uno de los cuatro sanatorios benéficos del país, en este caso quirúrgico propiedad de la Iglesia.

Salvo el Hospital Domínguez de Pontevedra, ningún otro hospital de este nivel urbano alcanza las 100 camas. En general, domina una red hospitalaria privada con una oferta variada de centros generales y quirúrgicos, generalmente entre 40 y 70 camas y en torno a los 50-60 empleados de media, complementada con psiquiátricos y con la tercera de las maternidades existentes en Galicia localizada en Ourense.

La particular crisis que afecta a la industria naval en Ferrol y la regresividad del territorio rural bajo la influencia de la capital lucense da lugar a que estas dos ciudades manifiesten un escaso atractivo para el capital privado. No obstante, las características socioeconómicas y geodemográficas de Ferrol y Lugo pueden ser un interesante espacio de inversión para el amplio sector sociosanitario, esencialmente para todas las actividades asistenciales directamente relacionadas con el envejecimiento poblacional. Y más cuando el sistema público no le está dedicando al problema del envejecimiento la atención que realmente se merece. A pesar de haber incluido en un mismo grupo a estas dos urbes, sus respectivas estructuras hospitalarias presentan escasas similitudes.

La infraestructura hospitalaria privada en la provincia de Lugo es la menor de las provincias gallegas. Únicamente se contabilizan dos centros hospitalarios, ambos localizados en la capital provincial. La importancia del espacio rural, la regresión demográfica y el fuerte envejecimiento en gran parte del territorio provincial influyen decisivamente en el escaso interés del capital privado por la inversión sanitaria en un espacio de estas características. En total, la provincia contabiliza 156 camas particulares y unos 133 trabajadores. Los dos centros de la ciudad de Lugo son de características similares. Ambos son privados no benéficos, de carácter general y de tamaño medio.

Por su parte, la sexta ciudad más poblada de Galicia y la que más ha sufrido las consecuencias de la reconversión industrial y crisis económica posee una escasa y singular oferta sanitaria privada. Ferrol tiene 81.991 habitantes (1999), es la ciudad gallega que más población pierde en la última década y su larga crisis se manifiesta en un escaso dinamismo socioeconómico y demográfico. Esta situación se va a observar claramente en el análisis de un servicio privado de alto nivel como es el sanitario. Esta ciudad, a pesar de su situación geoestratégica y su cierta importancia en la vida económica y social del país, sólo contabiliza un centro hospitalario privado, el Hospital General Juan Cardona (Santo Hospital de Caridade).

$\mathrm{Si}$ atendemos al total de camas instaladas y trabajadores del sector por ciudad, Ferrol ocuparía una posición importante en el conjunto de Galicia, superior a los indicadores de otras urbes como Santiago o Lugo. Sin embargo, la expresión de crisis socioeconómica se constata al analizar este tipo de recursos. La concentración hospitalaria en las principales ciudades responde a objetivos económicos de búsqueda de demanda, como sucede en cual- 


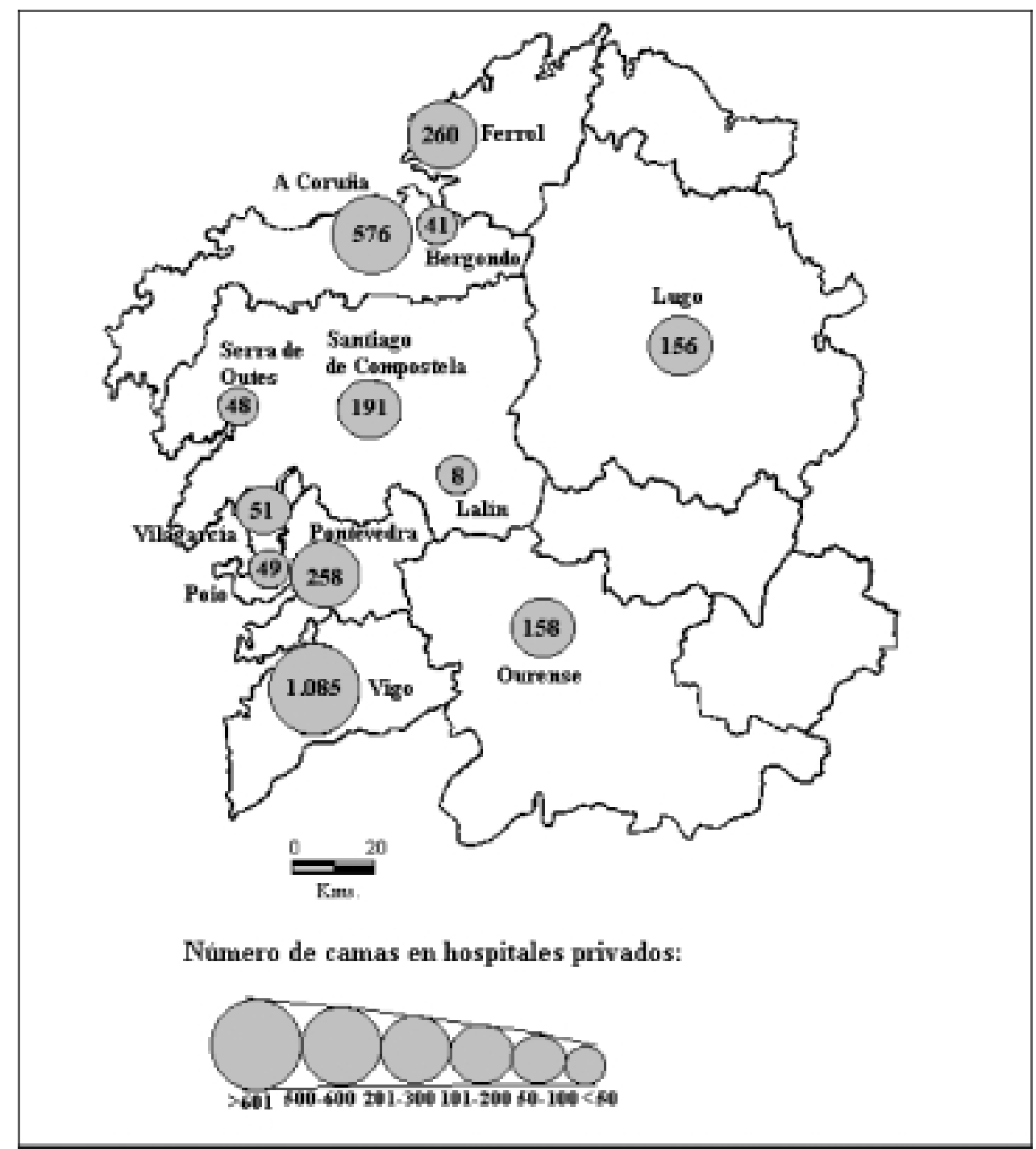

Fuente: Consellería de Sanidade e Servicios Sociais. Elaboración propia.

MAPA 2. Camas instaladas por municipio, 2000.

quier otra actividad económica sobre todo de carácter privada. No obstante, Ferrol no posee ni tan siquiera un hospital privado con ánimo de lucro, lo que nos da a entender que esta ciudad, también en este aspecto, no es atractivo a los intereses del capital, a la inversión en un servicio privado destinado fundamentalmente a población urbana y de medio/alto poder adquisitivo. Si el sector hospitalario privado no se instala en Ferrol debe entenderse porque el mercado no lo demanda, lo que define la peculiaridad en el comportamiento urbano de este núcleo eminentemente industrial. 


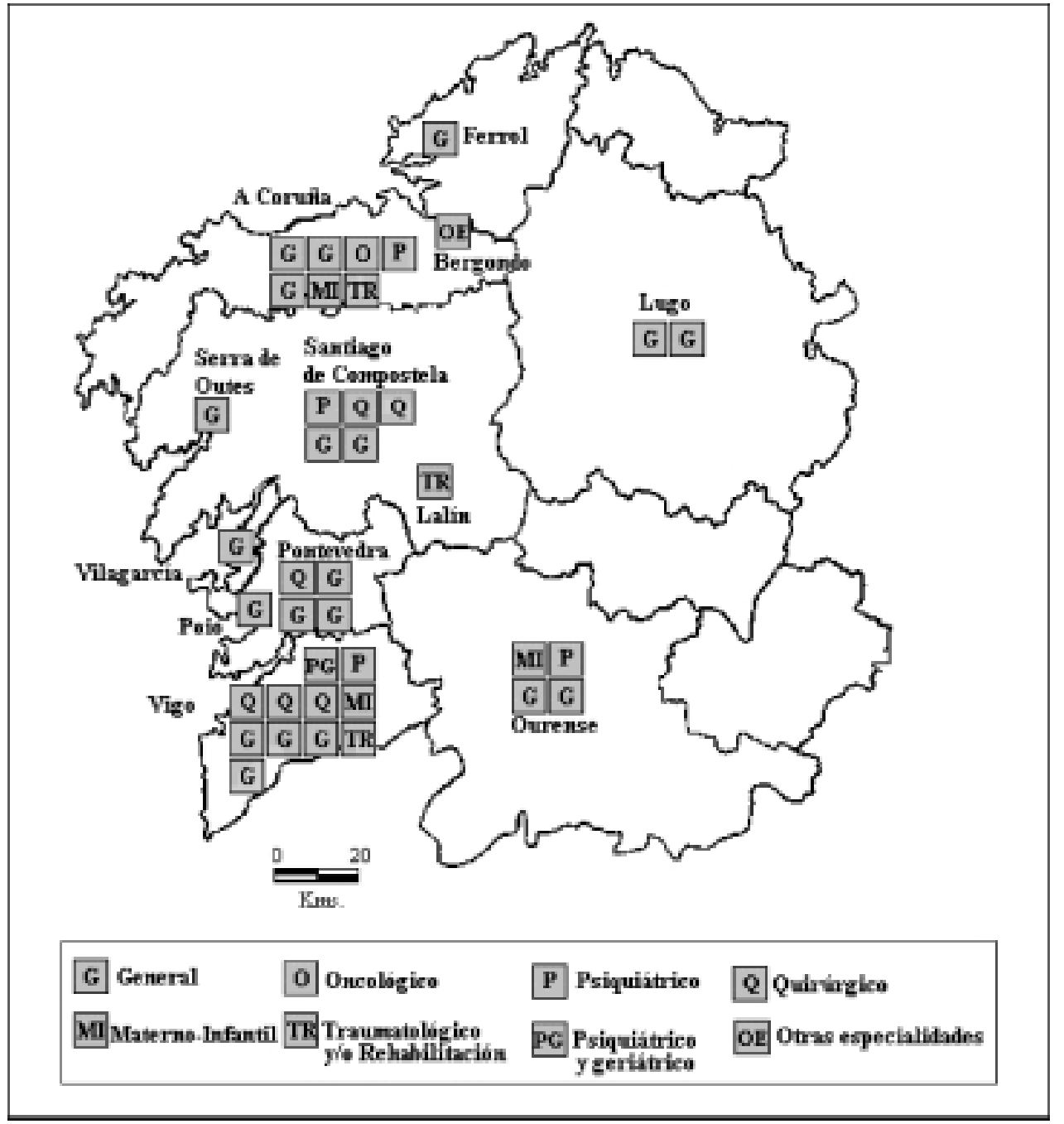

Fuente: Consellería de Sanidade e Servicios Sociais.

MAPA 3. Localización de hospitales por finalidad asistencial, 2000.

No obstante, Ferrol poseía un cierto dinamismo con anterioridad a la reconversión industrial, al poseer varios centros privados no benéficos. Todos ellos cerraron a partir de mediados de la década pasada ante las dificultades de supervivencia en una población en crisis, como sucedió con el Sanatorio San Javier. Hoy en día, la oferta privada se reduce a un centro benéfico, propiedad de la Iglesia, de carácter general y de importantes dimensiones. Un centro que, como una peculiaridad más, se convierte en el de mayor tamaño de toda la provincia y en el segundo de Galicia. 
En el nivel urbano inferior, las dotaciones en Vilagarcía, Lalín, Poio y Bergondo pueden correr el mismo camino que los hospitales de ámbito comarcal que han dejado la actividad en la segunda mitad de la década de los 1990 (Clínica Alameda de O Carballiño y Asimédica Virgen de la Luz de Monforte de Lemos), motivado sobre todo por la imposibilidad de competir con sanatorios tecnológicamente más avanzados (incluidos los del sector público) y por su inserción en espacios socioeconómicamente regresivos. El primero de ellos (Policlínica Médico-Quirúrgica Monte Xiabre de Vilagarcía) difícilmente podrá subsistir en una pequeña área de salud de unos 67.000 habitantes que recientemente ha inaugurado su correspondiente hospital público de referencia (Fundación Pública Hospital de O Salnés). La vitalidad de la capital de O Deza logra mantener abierto un pequeño hospital especializado que busca evitar los desplazamientos de sus habitantes a las clínicas de Santiago o Pontevedra. Mientras tanto, los sanatorios de Bergondo y Poio debemos entenderlos como localizaciones periféricas de la estructura hospitalaria de A Coruña y Pontevedra respectivamente, más que una peculiar oferta sanitaria en estos municipios.

Para finalizar hagamos una especial referencia al más interesante de los dispositivos hospitalarios en municipios no urbanos, como es el de Serra de Outes. El único hospital privado gallego que ha optado por una localización en un espacio rural es el denominado CENGAS I (Centro Galego de Saúde) en el término de Serra de Outes, distante unos 38 kilómetros de Santiago de Compostela. Éste representa un caso paradigmático de los nuevos modelos de gestión público/privada experimentados en Galicia, sin continuidad e inmerso en una grave crisis financiera. La introducción de nuevos modelos de gestión en la sanidad pública tendentes a la reducción del gasto y aumento de la iniciativa privada en la prestación de servicios públicos lleva a que en 1992 se cree el CENGAS I, S.A.

Este complejo sanitario nace por iniciativa privada en febrero de 1992 y entra en funcionamiento en 1995 con el objetivo de dar servicio sobre todo a las comarcas de O Barbanza y Costa da Morte, que engloban a 17 municipios y unos 158.000 habitantes. Este territorio, que está desprovisto de servicios hospitalarios privados y que poseía una oferta pública fuera de su comarca (Santiago de Compostela), puede verse beneficiado con la inauguración de este nuevo hospital general situado a medio camino entre las dos comarcas más desasistidas de la provincia. Este centro, aunque de iniciativa privada, se creó pensando en el concierto especial que establecería con la Consellería de Sanidade por el cual atendería a pacientes del sistema público residentes en esas comarcas. Se convertiría en su hospital «público» de referencia, de manera similar al sistema de concierto establecido con PO.VI.SA. para ofertar servicio a una parte del Área de Saúde de Vigo. Por tanto, aunque de origen y diseño privado, se había planificado con el objetivo principal de dar cobertura a los beneficiarios de la Seguridad Social, en base a un sistema mixto de sanidad.

Hasta aquí, la postura es hasta cierto punto innovadora para la fecha en Galicia. Sin embargo, la excesiva dependencia que los centros privados mantienen del sistema público y la experimentación constante en los modelos de gestión público-privado ha modificado sus planteamientos iniciales. Es decir, el centro firma un convenio con la Xunta de Galicia pero no se convierte en hospital de referencia para esas comarcas sanitarias, por lo cual los beneficiarios no tienen que ser obligatoriamente atendidos en este sanatorio. Esta situación propicia una escasa afluencia de pacientes del sistema público, que se decantan claramente por el C.H.U. Xeral-Xil Casares de Santiago (ahora Clínico Universitario), y todavía menor del privado dada su localización en un espacio rural. No olvidemos que en las escasas ocasiones que la población rural demanda asistencia privada, suele optar por los localizados en centros urbanos, en este caso de Santiago de Compostela. Por tanto, la Xunta de Galicia no ha 
logrado su objetivo de dar asistencia hospitalaria a más de 150.000 habitantes de la Galicia costera, lo que provoca una escasa reducción de la saturación hospitalaria pública en Santiago, que a penas se percata de la existencia de este nuevo hospital. Y, por otro lado, el complejo fracasa como asistencial público concertado y, dada su localización y las características sociodemográficas de su área de influencia, tampoco obtiene la afluencia privada planificada y deseada.

Éste constituye la primera tentativa de introducción de los nuevos modelos de gestión públicos con participación privada en Galicia. Posteriormente, la Xunta de Galicia tenía por objetivo trasladar esta experiencia de hospital comarcal a otras áreas de salud o ZSAI (Zonas de Saúde de Atención Integrada o comarcas sanitarias) desprovistas de asistencia hospitalaria, como O Salnés o Verín. Sin embargo, la no obtención de los resultados espe-

Cuadro 1

MODELO DE DOTACIÓN HOSPITALARIA PRIVADA SEGÚN EL RANGO URBANO EN GALICIA

\begin{tabular}{|c|c|c|}
\hline Red urbana & Finalidad asistencial & $\begin{array}{l}\mathrm{N}^{0} \text { medio } \\
\text { de camas }\end{array}$ \\
\hline $\begin{array}{l}\text { Ciudades rectoras de la } \\
\text { red urbana regional } \\
\text { (Vigo y A Coruña) }\end{array}$ & $\begin{array}{l}\text { NIVEL 1. Influencia provincial: } \\
\text { - 1-2 Generales de gran tamaño } \\
\text { NIVEL 2. Influencia región urbana: } \\
\text { - } 2 \text { Generales de tamaño medio y pequeño } \\
\text { NIVEL 3. Complemento en especialidades: } \\
\text { - } 1 \text { Traumatológico/Rehabilitación } \\
\text { - 1 Materno-Infantil } \\
\text { - 1-2 Psiquiátricos } \\
\text { - Otros: } 3 \text { quirúrgicos / } 1 \text { oncológico }\end{array}$ & $\begin{array}{l}\Rightarrow 170 *(1) \\
\Rightarrow 90 \\
\Rightarrow 24 \\
\Rightarrow 29 \\
\Rightarrow 57 \\
\Rightarrow 40 / 100\end{array}$ \\
\hline $\begin{array}{c}\text { Ciudades medias en } \\
\text { proceso de } \\
\text { diversificación económica } \\
\text { (Santiago, Ourense y } \\
\text { Pontevedra) }\end{array}$ & $\begin{array}{l}\text { NIVEL 2. Influencia región urbana: } \\
\text { - } 1 \text { General de tamaño medio (SA y OUR) } \\
\text { - 1-3 Generales de tamaño pequeño } \\
\text { NIVEL 3. Complemento en especialidades: } \\
\text { - 1-2 Quirúrgicos (SA y PO) } \\
\text { - 1Psiquiátrico (SA y OUR) } \\
\text { - 1 Materno-Infantil (OUR) }\end{array}$ & $\begin{array}{l}\Rightarrow 78 \\
\Rightarrow 47 \\
\Rightarrow 50 \\
\Rightarrow 26 \\
\Rightarrow 15\end{array}$ \\
\hline $\begin{array}{l}\text { Ciudades medias con } \\
\text { síntomas de } \\
\text { estancamiento } \\
\text { socioeconómico } \\
\text { (Lugo y Ferrol) }\end{array}$ & $\begin{array}{l}\text { NIVEL 2. Influencia región urbana: } \\
\text { - } 1 \text { General de gran tamaño }(F E) \\
\text { - } 2 \text { Generales de tamaño pequeño y medio }(L U)\end{array}$ & $\begin{array}{l}\Rightarrow 260 \\
\Rightarrow 78\end{array}$ \\
\hline $\begin{array}{l}\text { Pequeñas ciudades, } \\
\text { cabeceras comarcales y } \\
\text { periurbano (Vilagarcía, } \\
\text { Lalín, Poio y Bergondo) }\end{array}$ & $\begin{array}{l}\text { NIVEL 4. Influencia comarcal: } \\
\text { - } 1 \text { General de pequeño tamaño (VIL y POI) } \\
\text { - 1Traumatológico/Rehabilitación (LA) } \\
\text { - Otras especialidades (BER) }\end{array}$ & $\begin{array}{l}\Rightarrow 50 \\
\Rightarrow 8 \\
\Rightarrow 41\end{array}$ \\
\hline $\begin{array}{c}\text { Hospitalización en } \\
\text { espacio rural (Outes) }\end{array}$ & $\begin{array}{l}\text { NIVEL 5. Nuevos modelos de gestión: } \\
\text { - } 1 \text { General de pequeño tamaño }\end{array}$ & $\Rightarrow 48$ \\
\hline
\end{tabular}

Elaboración propia.*(1): Excluimos de la media a PO.VI.SA. 
rados provocó un giro en la tipología dotacional hospitalaria en las cabeceras comarcales gallegas. La administración pública sanitaria opta por la creación de Fundaciones Públicas, caso de la F.P. Hospital de Verín, la de O Salnés, Costa da Morte y O Barbanza. Y justamente la aplicación de este nuevo modelo fundacional incrementa todavía más la crisis del CENGAS I. Es decir, los nuevos centros comarcales recientemente inaugurados en Santa Uxía de Ribeira y Cee compartimentan a efectos hospitalarios el territorio que, en principio, pretendía cubrir el CENGAS I, con la formulación de áreas de referencia. De esta manera, la población de estas comarcas ven incrementadas sus respectivas ofertas hospitalarias, lo cual redunda en una pérdida importante de mercado para el CENGAS I.

Por tanto, las tendencias de expansión o de mantenimiento de una cuota fija de mercado se complica en demasía para este hospital. Tal y como sucede con otros centros, sus perspectivas de desarrollo pasan por una reconversión funcional. Pero tampoco aquí la situación se vislumbra demasiado clara. En su corta historia ha pasado de ser un hospital de carácter general para años más tarde convertirse en general-geriátrico. Situación que valora en su justa medida el proceso de envejecimiento y la importancia de las enfermedades crónicas y degenerativas, y su influencia sobre un incremento considerable de la estancia media. Pero en la actualidad de nuevo vuelve a definirse como general. Esta evolución tan agitada en tan pocos años le advierte un futuro muy incierto. Tengamos en cuenta que de 94 camas contabilizadas en 1998, sólo suma 48 en el 2000. En la actualidad y desde la entrada en funcionamiento de las dos fundaciones hospitalarias públicas en Ribeira y Cee, no mantiene ningún tipo de concierto con la administración sanitaria pública.

\section{Potencialidad económica y dependencia pública del sector hospitalario}

Dentro de la representación económica que ocupa la sanidad privada en el conjunto de la economía y del sector servicios en Galicia, el hospitalario mantiene una posición privilegiada, tanto por la facturación como por el empleo generado y la creciente inversión en equipos de alta tecnología. Utilizando diversas fuentes (Zona Franca de Vigo, El Correo Gallego y Seguridad Social) se estima que los hospitales privados gallegos facturaron un total de 23.022.914.000 pesetas en 1996, de los cuales el 52,74\% corresponden a los centros radicados en la provincia de Pontevedra. Es más, Vigo concentra más del $45 \%$ de la facturación privada gallega, lo que expresa el dinamismo del sector en la ciudad más poblada de Galicia con la existencia de una completa red asistencial y la ubicación en su término municipal del mayor hospital gallego (PO.VI.SA.), donde él sólo factura casi 7.500 millones de pesetas anuales.

No obstante, si bien este montante económico es reflejo de una demanda creciente de la atención privada, tiene también otra explicación más sencilla y fácil de detectar. La práctica cada vez más habitual de establecer conciertos entre el SERGAS y los hospitales privados con el objetivo de dar cobertura en determinadas especialidades y en cirugía para contribuir a reducir listas de espera, es común en la sanidad gallega. Aunque algunos no lo quieran aceptar, esta medida se inscribe en la introducción de estrategias de privatización en la sanidad, al facilitar un tipo de prestación no pública a la población adscrita a la Seguridad Social, en vez de incrementar el patrimonio público y la gestión directa por parte del SERGAS. Esta estrecha colaboración público-privado sustenta una buena parte de los hospitales privados, al menos los de menor tamaño, pasando a ser sus principales clientes los pacientes provenientes del sistema público. Por lo tanto, el establecimiento de conciertos con la sanidad pública se convierte en uno de los principales factores que explican el fortaleci- 
miento del sector sanitario privado. Y que se vendría a añadir a los nuevos comportamientos sociales, el debilitamiento y la deficiente imagen del sector público, y la posibilidad de los funcionarios de la administración pública en optar por los seguros médicos privados.

De los treinta y nueve sanatorios privados gallegos en 2000, veinte tienen establecidos algún tipo de concierto con el Servicio Galego de Saúde. Los que no mantienen dependencia económica de la administración pública son los localizados en los espacios no propiamente urbanos (Bergondo, Cee, Lalín, Poio y Vilagarcía) y la mayoría de los sanatorios urbanos especializados. Es decir, la práctica totalidad de los hospitales urbanos generales gallegos, sólo algún quirúrgico y el único oncológico de la Comunidad Autónoma tienen establecidos conciertos con el SERGAS. El resto de los especializados (psiquiátricos, traumatológicos, maternidades...) no mantienen relación económica y funcional. Estos coinciden habitualmente con centros de pequeño tamaño (menos de 50 camas) y con escasa presencia de alta tecnología. Es complicado demostrar si esta última característica condiciona negativamente la relación contractual con el SERGAS o si, por el contrario, es la falta de convenio con la administración la que no asegura unos ingresos económicos que facilite la inversión tecnológica. Sea como fuere, estos conciertos representan un incentivo económico esencial para los hospitales privados, ayudando al mantenimiento de su capacidad inversora y al gasto en tecnología, y facilitando la contratación de personal.

Lo que resulta evidente es la importancia de la aportación pública en la modernización y desarrollo del hospital, más cuando se llega a afirmar que los conciertos firmados con el SERGAS suponen entre el $20 \%$ y $30 \%$ de la facturación anual de los sanatorios privados (González, 1999; 212). En definitiva, la incorporación progresiva de conciertos ha asegurado la supervivencia económica de muchas clínicas o bien ha mantenido la capacidad inversora de otras muchas.

Como conclusión presentamos una matriz DAFO sobre el sector hospitalario gallego, valorando las nuevas tendencias en la sanidad pública, los cambios comportamentales e ideológicos en la sociedad, la estructura económica y empresarial del sector privado, entre otros. Esta matriz es el resultado de las conclusiones derivadas de la entrevista directa a más de treinta expertos en materia de salud en Galicia y que se enmarca en un proyecto de investigación sobre las necesidades de formación en la sanidad privada que he tenido ocasión de coordinar (González, 1998 y 1999).

Tabla 6

DISTRIBUCIÓN DE LOS HOSPITALES CON Y SIN CONCIERTO PÚBLICO (SERGAS) SEGÚN DIFERENTES VARIABLES

\begin{tabular}{|l|c|c|c|c|r|r|}
\hline & \multicolumn{3}{|c|}{ Con concierto } & \multicolumn{3}{c|}{ sin concierto } \\
\cline { 2 - 7 } & Camas & $\begin{array}{c}\text { Equipos alta } \\
\text { tecnología }\end{array}$ & $\begin{array}{c}\text { Facturación } \\
\text { (miles de ptas.) }\end{array}$ & Camas & $\begin{array}{c}\text { Equipos alta } \\
\text { tecnología }\end{array}$ & $\begin{array}{r}\text { Facturación } \\
\text { (miles ptas.) }\end{array}$ \\
\hline A Coruña & 857 & 19 & 7.471 .498 & 259 & 3 & 1.028 .500 \\
Lugo & 156 & 5 & 743.750 & 0 & 0 & 0 \\
Ourense & 120 & 5 & 1.381 .250 & 38 & 0 & 254.012 \\
Pontevedra & 1.037 & 16 & 10.603 .014 & 414 & 2 & 1.540 .890 \\
\hline GALICIA & 2.170 & 45 & 20.199 .512 & 711 & 5 & 2.823 .402 \\
\hline
\end{tabular}

Fuente: Consellería de Sanidade e Servicios Sociais. Elaboración propia. 
- Excesiva dependencia de la política sanitaria pública en materia de conciertos y convenios especiales.

- Gestión hospitalaria con insuficiente conocimiento de la demanda potencial y del territorio de su área de influencia.

- Falta de planes estratégicos de desarrollo.

- Sistemas de gestión y organización de empresas anticuados. Preponderancia de estructuras empresariales de carácter familiar.

— Escasa inversión en programas de I+D y de investigación clínica y sociosanitaria.

- Escasa preocupación por obtener buenos índices de calidad asistencial y de funcionamiento hospitalario. Los objetivos de atención personalizada y rápida atención médica son más fácilmente percibidos por el paciente y su familia.

- Bajo nivel de contratación de personal sanitario facultativo (sobre todo especializado). Predomina el «médico colaborador», que está más preocupado por su clientela y beneficio personal que por un funcionamiento integrado del centro.

- Lenta adaptación a las nuevas necesidades sociosanitarias derivadas de cambios demográficos (envejecimiento de la población).

- Incremento del coste económico debido a la incorporación de nuevos procesos y tecnologías. El minifundismo empresarial dificultará tanto la implantación de tecnologías como la competencia con posibles inversores externos.

- Servicios de urgencia deficitarios (falta de personal sanitario especializado y tecnología) sobre todo en los hospitales de tamaño medio y pequeño.

- Las nuevas tendencias quirúrgicas y cambios en los procesos. La cirugía de corta estancia y la tendencia a la reducción de los días de hospitali-

\section{AMENAZAS}

- Los grandes grupos empresariales aseguradores concentran y monopolizan el sector. Incremento del control en la gestión empresarial por parte de las compañías de seguros médicos privados.

- Competencia desleal propiciada por el sistema sanitario público con la creación de las fundaciones hospitalarias (gestión privatizada pero financiada con cargo al presupuesto de la Administración Autonómica y con una población de referencia asegurada). Situación que afectará, en mayor medida, a los centros privados con un área de atracción fundamentalmente rural.

- La posible aplicación de una ley de acreditación hospitalaria tanto a nivel estatal como de la Unión Europea dificultará enormemente la supervivencia de muchos hospitales gallegos, debido a que algunos de ellos no obtienen los mínimos indicadores de calidad exigibles. La reconversión para adaptarse a estos mínimos obligaría a una inversión demasiado importante, que muchos no lograrían o no estarían dispuestos a acometer.

- A pesar de que pueda actuar igualmente como una oportunidad, la unión monetaria en la U.E. y la eliminación de las fronteras permitirá a centros del exterior competir en nuestro país con ventajas competitivas evidentes, sobre todo por una mayor experiencia de las clínicas del centro y norte de Europa en unos mercados privados más desarrollados y competitivos.

- La escasa inversión en formación y en investigación influyen, decisivamente, en la pérdida de calidad. El aumento del nivel cultural en la población de clase media-alta, los que en mayor medida optan por la atención privada, contribuye a que puedan llegar a percibir estas deficiencias, con las consecuencias negativas que esto puede significar. 


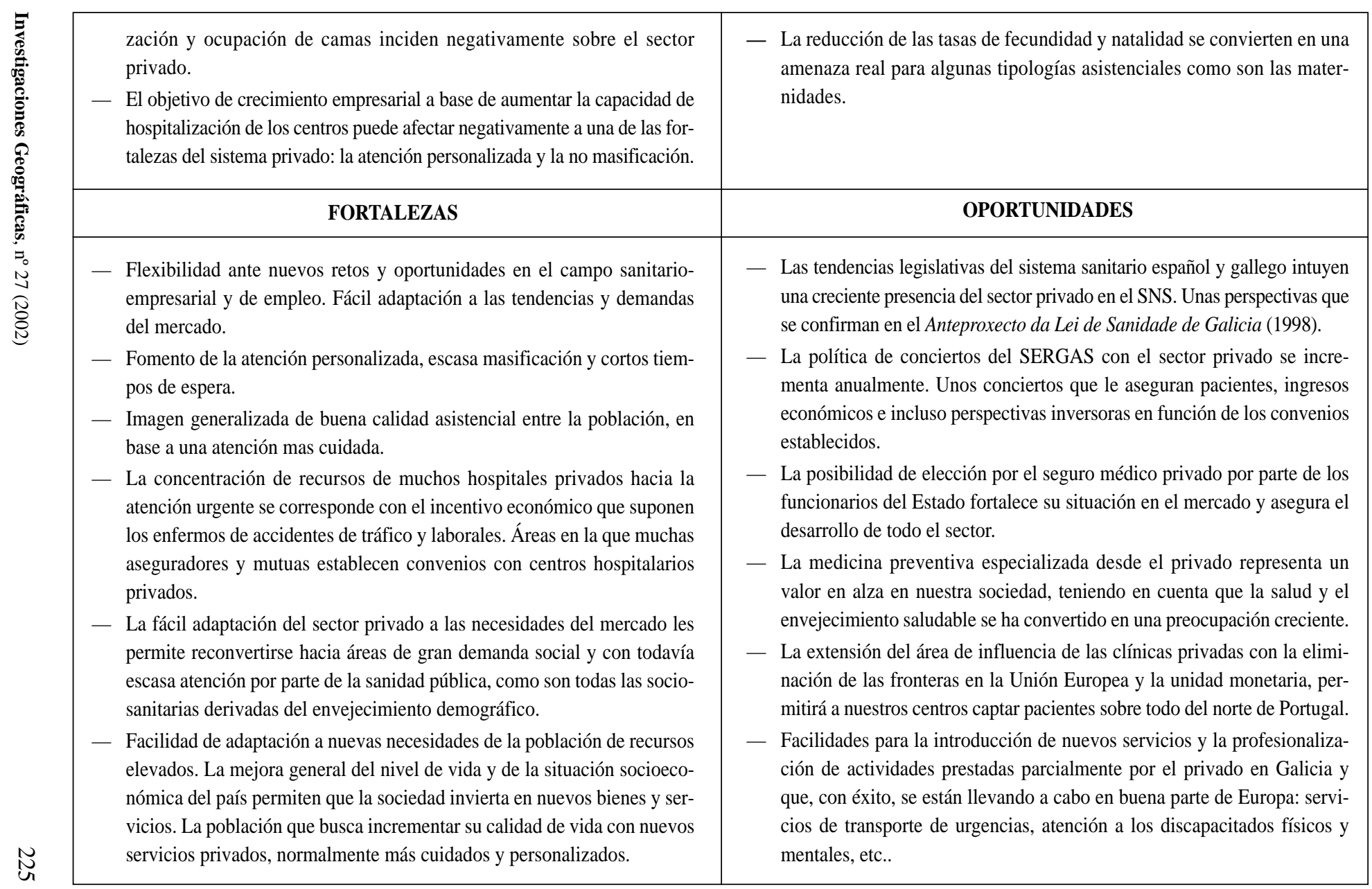




\section{Bibliografía}

AA.VV. (2000): Informe del sector asegurador gallego. Datos 1999. Vigo: INADE, Instituto Atlántico del Seguro.

AA.VV. (2000): El mercado asegurador por provincias. Datos 1999. Madrid: ICEA.

BARDINA i BOIXADERA, J.R. (1995): Aseguramiento privado. Todo Hospital (Madrid), núm. 121, 21-25.

CONSELLERÍA DE SANIDADE E SERVICIOS SOCIAIS (2000): Catálogo de hospitais Galicia 1999. Santiago: Xunta de Galicia.

CONSELLERÍA DE SANIDADE E SERVICIOS SOCIAIS (2000): Guía de servicios 2000. Santiago de Compostela: Xunta de Galicia.

ESTEVE, F. (1989): Bienestar y economía posicional. In Muñoz de Bustillo, Crisis y futuro del Estado de Bienestar, (101-123). Madrid: Alianza Universidad.

FERNÁNDEZ-MAYORALAS, G. y RODRÍGUEZ, V. (1997): Niveles y distribución geográfica de la cobertura sanitaria en España. Estudios Geográficos (Madrid), núm. 228, 377-395.

GONZÁLEZ PÉREZ, J.M. (Coord.) (1998): Necesidades de formación no sector da sanidade privada na provincia de Pontevedra. Santiago de Compostela: IFES-UGT, Forcem, Universidade de Vigo.

GONZÁLEZ PÉREZ, J.M. (Coord.) (1999): Necesidades de formación no sector da sanidade privada nas provincias de A Coruña, Lugo y Ourense. Santiago de Compostela: IFES-UGT, Forcem, Universidade de Vigo.

HERNÁNDEZ PASCUAL, J. (1989): Mercado y regulación administrativa en el seguro sanitario privado. Revista de Sanidad e Higiene Pública (Madrid), núm. 63, 11-18.

JOHNSON, N. (1990): El Estado del Bienestar en transición. La teoría y la práctica del pluralismo de Bienestar. Madrid: Ministerio de Trabajo y Seguridad Social.

LÓPEZ i CASANOVAS, G. y JOFRE i BONET, M. (1995): El seguro sanitario dentro del sistema sanitario español: algunas reflexiones contextuales. Todo Hospital (Madrid), núm. 115, 917.

MISHRA, R. (1989): El Estado de Bienestar después de la crisis: los años 80 y más allá. In Muñoz de Bustillo, Crisis y futuro del Estado de Bienestar, (59-79). Madrid: Alianza Universidad.

NAVARRO, V. (1995): El debate sobre la separación entre las funciones de financiación y provisión de servicios en el Estado de Bienestar y su relevancia para España. Gaceta Sanitaria (Madrid), núm. 9, 202-209.

ORTÚN RUBIO, V. (1989): Público-privado, en sanidad. Revista ROL de Enfermería (Madrid), núm. 126, 12-14.

SÁNCHEZ BAYLE, M. (1998a): La contrarreforma sanitaria. Revista de Administración Sanitaria (Madrid), núm. 5 (vol. II), 51-61.

SÁNCHEZ BAYLE, M. (1998b): Hacia el Estado del malestar. Neoliberalismo y política sanitaria en España. Madrid: Los Libros de la Catarata.

SERVICIO GALEGO DE SAÚDE (2000): Memoria SERGAS 1999. Santiago de Compostela: Xunta de Galicia.

SOLER FÁBREGAS, M. (1995): Medicina privada. Todo Hospital (Madrid), núm. 121, 49-54. 